\title{
So Much to Unlearn
}

\author{
David Zeigler
}

Published online: 17 August 2011

(C) Springer Science+Business Media, LLC 2011

\section{Keywords Nature of science}

Science does not just change, it builds cumulatively on the past. Scientists make mistakes aplenty, and in fact this is how science progresses. The self-correcting feature of the scientific method is one of its most powerful assets. (Michael Shermer)

One of the great strengths of science, yet a sometimes troubling one for those involved in science, is that as scientists continue to accumulate more knowledge, some of our older "confident" precepts are weakened, modified, or even discarded. The strength in this is that change is allowed to occur when that change gives us a more accurate and parsimonious explanation of the material universe. We need not (must not) cling to outdated and disproven concepts and paradigms when they have been shown to lack accuracy and explanatory power-especially so when alternate new concepts and paradigms are formulated that provide a better objective fit with reality. There have been, and continue to be, minor and major changes necessitated by new discoveries and data, and one must "keep up" in order to be current in the numerous scientific disciplines. This applies not only in cutting-edge research, where small changes come at a rapid pace, but also to the broader areas of knowledge where those of us who teach in undergraduate courses are responsible for maintaining "currency."

Only in the last 100 years did we learn that the Milky Way was not the universe, but instead was only one of

D. Zeigler $(\bowtie)$

University of North Carolina at Pembroke,

Pembroke, NC, USA

e-mail: david.zeigler@uncp.edu many other galaxies - totaling now in the billions. It is hard to imagine a more surprising and major example of a revolution or paradigm shift in scientific understanding. Coming into more recent times, any source which continues to state the outdated dogma that all chemical energy utilized by organisms originated in photosynthesis is flatly wrong now that numerous communities based on chemosynthetic prokaryotes (most of them surrounding deep sea hydrothermal vents) have been discovered - and only within the last 35 years or so.

Additions to scientific knowledge most often come in the form of new "bits" of knowledge that do not require much restructuring of the current knowledge in that respective area. But some discoveries like that of Hubble's concerning the galaxies altered existing knowledge to the extent that we had to "unlearn" or uninstall some previously accepted fundamental concepts and substitute the distinctly new. Over my career as a biologist, I have had to go through this unlearning and correcting process many times as scientific knowledge has evolved, yet I am still taken aback when some new discoveries shake up the knowledge I came to think of as firmly established.

Not being a cell and molecular biologist, I am not sure how our earlier estimates concerning the number of human genes were formulated, but many sources stated anywhere from 100,000-150,000 genes as the probable number, and of course one of the greatest surprises to come out of the human genome project was the much lower estimate of around 21,000 human genes. There have been several other genomic surprises, with undoubtedly many more to come as genomes are elucidated more fully.

For a number of years around and after the human genome sequencing, the idea that at around $98 \%$ of the 
genome was "junk" was widely stated and taken as very probably true, but currently that idea is being questioned as some of this non-coding DNA is now suspected to have important regulatory or other functions. A reliable answer to this question will undoubtedly take a few more years to nail down, but those teaching genetics and cell biology certainly need to keep track of new developments in this area.

In marine science, I had to unlearn the still common misconception that all coral reefs are located in shallow warm waters between $30^{\circ}$ north and $30^{\circ}$ south latitudes, with Bermuda typically stated as the one exception at around $32^{\circ}$ north. Starting only in the late 1990s, massive deep-water coral reefs were discovered in the cold waters off of Norway and Ireland, with several more locations now known from the Gulf of Mexico, the Pacific, and in certain areas around Africa (Levinton 2009). These deep-water ahermatypic corals lack the photosynthetic mutualistic zooxanthellae required by the tropical shallow-water hermatypic corals, so they grow more slowly but can grow at great depths.

I have likewise had to unlearn numerous points of evolutionary inference in zoology over the last 25 years. When I was starting out in biology back in the 1970s, the distinction between whether an animal group had a true coelom or a pseudocoelom was considered a major character useful in understanding its phylogeny, with all the pseudocoelomates then being grouped into the Phylum Aschelminthes. Now of course the Aschelminthes name has been all but forgotten with its former group members (once classes) now split out into several distinct phyla such as the Rotifera, the Nematoda, the Kinorhyncha, and others (Ruppert et al. 2004). Coelom similarities are now recognized to have come about through different evolutionary/developmental pathways and are in many cases considered to be convergent rather than homologous, so this once important coelom/pseudocoelom distinction is now one of much less phylogenetic import.

Whereas the previous example was a refinement involving phylogenetic splitting, several previously recognized animal phyla have now been fused as more genomic, ultrastructure, and developmental data have become available. Beardworms (pogonophorans) and spoonworms (echiurans) were previously separate phyla, but are now known to be highly derived Annelids (Lecointre and Guyader 2006). Likewise, the former phylum of tongueworms (the Pentastomida) is now recognized as a Class of Crustaceans (Ruppert et al. 2004). Even a former protistan phylum, the Myxozoa has been discovered to be a highly derived parasitic group of Anthozoan Cnidarians (Ruppert et al. 2004). One of the most surprising and near unbelievable developments is the finding that acanthocephalans, which have long been considered a separate phylum, may in fact be highly derived rotifers (Lecointre and Guyader 2006)! Due to the dramatic differences in form, size, and lifestyle between the parasitic acanthocephalans and the mostly freeliving microscopic rotifers, this new understanding is even more surprising, and therefore difficult to achieve the required "unlearning."

Another major example of change has been the proliferation of phyla in the Kingdom Protoctista. I recall back when I was finishing my B.S. in Biology (mid 1970s), the most current textbooks listed only around 8-9 protist phyla. Today the protist phyla are almost triple that number with new higher-level groupings like the "Alveolata and Rhizaria" now becoming standard terminology (Lecointre and Guyader 2006). Though I sometimes slip and utter the term protozoa, I quickly recover and explain that this term no longer refers to any valid natural group or clade, but was once used to refer to any unicellular eukaryote that was heterotrophic and had the ability to move.

Another new change in evolutionary thinking, seemingly well supported by recent fossil finds, involves the role of the first "legs" in the fish that led to the early land tetrapods. The standard interpretation biologists once learned and taught was that legs evolved in fish so that they could haul themselves overland from small shrinking pools to larger ones when rivers or estuaries dried up in times of low rainfall-effectively allowing them to locate larger and less stagnant pools of water that were still habitable where they might survive until water levels rose again. The new interpretation based on fossils of Acanthostega and Icthyostega suggests that early legs evolved from fins to allow effective locomotion in shallow-water environments dense with aquatic vegetation. In short, the first vertebrate legs evolved to allow these fish to push and pull themselves along the bottom and over or through aquatic vegetation in shallow water-perhaps even using them to do "pushups" to lift their heads up to breath air into their lungs when the waters did occasionally become stagnant and oxygen-depleted (Zimmer 1998). Only once having evolved a leg-like structure were these appendages later exapted for terrestrial meanderings in one or more later descendants.

In attempting to gain a current understanding of evolution, the topics of contingency (vs. progress), symbiosis, horizontal gene transfer, genomics, punctuated equilibrium, sympatric speciation, opportunity, and development would be essential components, yet all these topics were either absent or only briefly touched on in evolution textbooks of only 20 years ago (or in the two evolution courses I took in the late 1970s). Our understanding of evolution is most definitely evolving and becoming more complex as the years go by.

I could go on for several more paragraphs listing other changes which unsettled my earlier understandings of nature, biology, and evolution, and others could of course do the same-adding examples of which I as an invertebrate zoologist am not familiar. So the obvious message 
which most readers of this article already know is that the body of scientific knowledge evolves constantly by both additions of new data, new understandings of current data, and by the loss or deletion of old concepts which have failed to be supported by new data. In short, we must learn new things and unlearn some old things to remain current in the sciences. This is, I trust, obvious to most readers, but I believe it important to occasionally restate and be reminded of the obvious - especially so for those of us who teach undergraduates - in part because we need to make the absolute necessity of this evolutionary process clear to our students, some of whom may otherwise assume that all scientific knowledge is "set in stone." Science demands the open mind, willing to look at the new evidence, even if it means giving up a long-held and even cherished concept, and even if it means unlearning a lot of what we initially learned in our science classrooms and laboratories.

\section{References}

Lecointre G, Guyader H. The tree of life: a phylogenetic classification. Cambridge: Harvard University Press; 2006.

Levinton JS. Marine biology: function, biodiversity, ecology. 3rd ed. NY: Oxford University Press; 2009.

Ruppert E, Fox RS, Barnes RD. Invertebrate zoology. 7th ed. Belmont: Brooks/Cole; 2004.

Zimmer C. At the water's edge. NY: The Free Press; 1998. 